\title{
Molecular and Polymeric Ceramic Precursors
}

\section{Research Progress Report}

Project Period: December 1, 1990 - November 30, 1993

Budget Period: December 1, 1992 - Nobember 30, 1993

Larry G. Sneddon

The Trustees of the University of Pennsylvania

Philadelphia, Pennsylvania 19104

\section{NOTICE}

This report was prepared as an account of work sponsored by the United States Government. Neither the United States nor the Department of Energy, nor any of their employees, make any warranty, express or implied, or assumes any legal liability of responsibility for the accuracy, completeness, or usefulness of any information, apparatus, product or process disclosed or represents that its use would not infringe privately-owned rights.

May, 1993

Prepared for

The U.S. DEPARTMENT OF ENERGY

AGREEMENT NO. DE-FG02-87ER13732 


\title{
TECHNICAL REPORT
}

Grant No. DE-FG02-87ER13732

Project Title

"Molecular and Polymeric Ceramic Precursors"

\begin{abstract}
The development of new methods for the production of complex materials is one of the most important problems in modern solid state chemistry and materials science. This project is attempting to apply the synthetic principles which have evolved in inorganic and organometallic chemistry to the production of technologically important non-oxide ceramics, such as boron nitride, boron carbide and metal borides. Our recent work has now resulted in the production of new polymer systems, including poly(B-vinylborazine), polyvinylpentaborane and polyborazylene, that have proven to be high yield precursors to boron-based ceramic materials. Current work is now directed toward the synthesis of new types of molecular and polymeric boroncontaining species and an exploration of the solid state properties of the ceramics that have been produced in these studies.
\end{abstract}




\section{Summary of Scientific Progress}

Many inorganic polymers exhibit enhanced properties compared to typical organic polymers, including thermal and chemical stability, electronic conductivities and preceramic properties. ${ }^{1}$ This project is exploring the synthesis, characterization and applications of new inorganic polymier systems, with a particular interest in the development of processable polymeric precursors to important solid state materials. A major focus of our work in the last three years has dealt with the synthesis and properties of new preceramic polymers.

Because of their high strengths, low densities, high temperature and chemical stabilities, and controllable electronic properties, ceramics and ceramic-composite materials are in the forefront of advanced materials technologies. Although most ceramic materials can already be produced in large quantities via conventional powder techniques, these materials, due to their brittle and refractory properties, are not easily formed into complex shapes. Therefore, applications of advanced ceramics as films, fibers, coatings or other complex shaped materials will require new ceramic synthesis and processing methods. Polymeric-precursors have now proven to be attractive synthetic routes to solid state materials that enable their formation in processed forms. Such methods offer a number of advantages ${ }^{2}$ including: (1) precise control over polymer stoichiometry and composition which can be systematically varied to optimize ceramic properties, (2) the ability to form the polymer into a desired shape or thin-film followed by conversion to the ceramic with retention of form, and (3) low temperature decomposition, enabling ceramic formation under milder conditions than those used in conventional techniques.

There are already several commercialized polymeric precursors to siliconbased ceramics, including the polycarbosilanes ${ }^{3}$ used to form silicon-carbide "Nicalon" fibers and the polysilazane ${ }^{4}$ precursors to silicon nitride. Because of their technological importance for both structural and electronic applications, our work has focused on the development of new polymeric precursors to boron-based ceramic materials including, boron carbide, boron nitride and metal borides and most recently, composites such as BNC or SiNCB ceramics. As described in the following sections, our work during the last three years has resulted in the development new polymeric precursors to each of these systems.

\section{Polymeric Precursors for Boron Nitride.}

Graphite and $h-B N$ exhibit similar strength and ablation properties, as well as anisotropic thermal expansions and conductivities; however, unlike graphite, $h-B N$ is oxidatively stable in air to $900^{\circ} \mathrm{C}$ and is an electrical insulator. This combination of properties has led to a number of unique structural and electronic applications for $h$ $\mathrm{BN}$, but many of these uses require the formation of the ceramic in a processed form. 5 We have now synthesized several new inorganic polymers, including the borazine- 
based polymers polyvinylborazine and polyborazylene, and shown that they can be used to obtain boron nitride in a variety of forms, including films and fibers. 6

Polyvinylborazine. The production of polyvinylborazine, an inorganic analogue of polystyrene, initially required the synthesis of the previously unknown compound vinylborazine, $\mathrm{CH}_{2}=\mathrm{CH}-\mathrm{B}_{3} \mathrm{~N}_{3} \mathrm{H}_{5}$. This was achieved via the metal-catalyzed reaction of borazine with acetylene and this reaction has allowed the large scale production of this monomer. ${ }^{7}$

$$
\mathrm{B}_{3} \mathrm{~N}_{3} \mathrm{H}_{6}+\mathrm{HC} \equiv \mathrm{CH} \stackrel{\mathrm{RhH}(\mathrm{CO})\left(\mathrm{PPh}_{3}\right)_{3}}{\longrightarrow}
$$

Insoluble polymeric materials result from thermally induced polymerizations of pure liquid B-vinylborazine, but it was found that solution polymerizations using the free radical initiator AIBN proceed smoothly to form soluble homopolymers. The spectroscopic data support a polystyrene-type structure. ${ }^{8}$

These new polyvinylborazine polymers have now been used to produce, depending upon pyrolysis conditions, a variety of ceramic materials, ranging from black, high carbon content materials to white h-BN. In each case, however, the polymer/ceramic conversion was found to take place with both high ceramic and chemical yields and give materials with $\mathrm{B} / \mathrm{N}$ ratios of 1.0. Best results for the production of pure $h-B N$ were obtained from the pyrolyses under an ammonia atmosphere, which produced white, crystalline $h-B N$ with only $0.27 \%$ carbon and $0.15 \%$ hydrogen impurities, corresponding to an empirical formula of

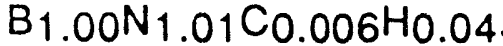

Polyborazylene. The poly(B-vinylborazine) described in the previous section shows excellent conversions to boron nitride, but because of the carbon backbone this polymer requires pyrolyses under ammonia atmosphere to achieve low-carbon boron nitride. In an effort to develop new boron nitride precursors that would give improved ceramic yields and/or not require the use of ammonia during the ceramic conversion step, we initiated investigations of the syntheses of poly(borazylene) polymers, such as shown in the Figure below, composed of linked borazine rings analogous the organic poly(phenylene) polymers. Such polymers were also of particular interest because of their potentially high ceramic yields (95\%) and their close structural relationship to boron nitride.

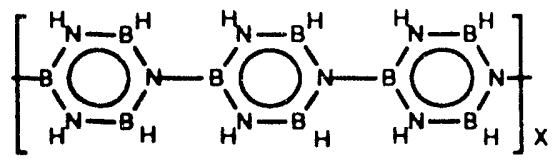

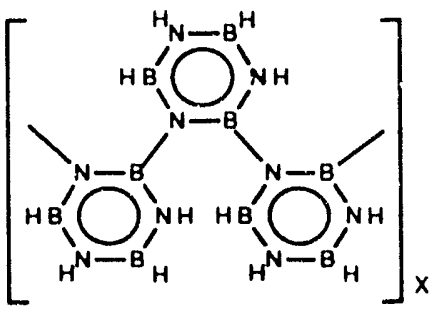

Initial investigations focused on metal catalyzed synthetic routes; however, during the course of these studies we discovered 9 that controlled thermolysis of liquid borazine in vacue at moderate temperatures results in nearly quantitative 
dehydropolymerizations to form soluble polyborazylenes. The resulting polymers are highly soluble in polar solvents with a typical $M_{w} 7,600$ and $M_{n} 3,400$. Elemental analyses and SEC/LALLS/UV studies support a branched-chain or partially crosslinked structure.

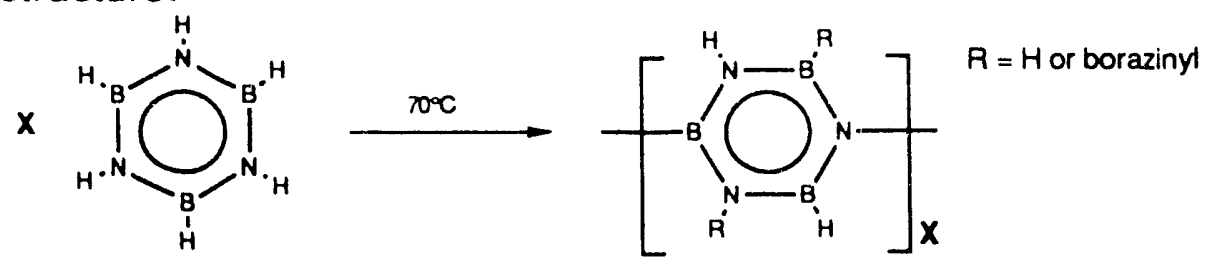

Bulk pyrolyses of the polymer under either argon or ammonia to $1200^{\circ} \mathrm{C}$ result in the formation of white boron nitride powders in excellent purities and ceramic yields $(85-93 \%)$.

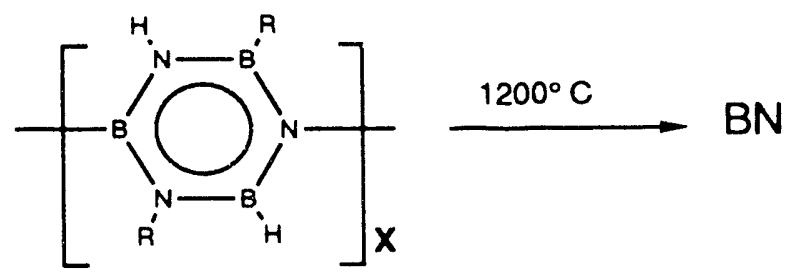

Studies ${ }^{10,11}$ of the polyborazylene/boron-nitride ceramic-conversion reaction have shown that both polyborazylene and a crosslinked intermediate material obtained by heating at $400^{\circ} \mathrm{C}$, exhibit $X$-ray patterns consistent with a layered structure. This observation suggests a simple process for the conversion of the polymer to boron nitride, involving a dehydrocoupling reaction between the B-it and $\mathrm{N}$-H groups on adjacent polymers resulting in a 2-dimensional-crosslinking of the polymer.<smiles>c1ncncn1</smiles>

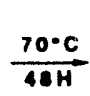

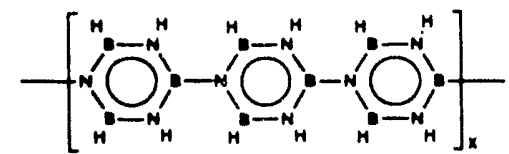

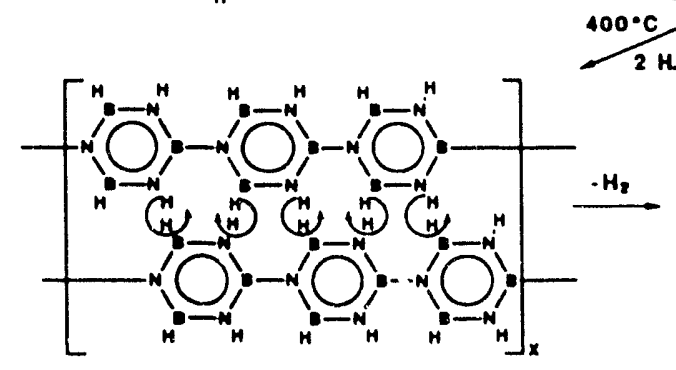

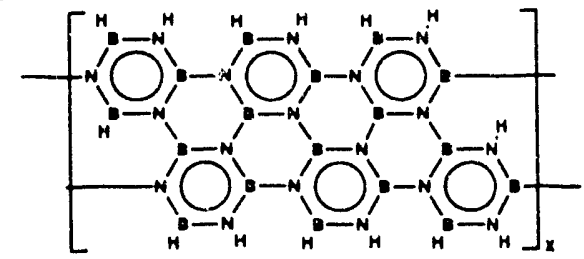

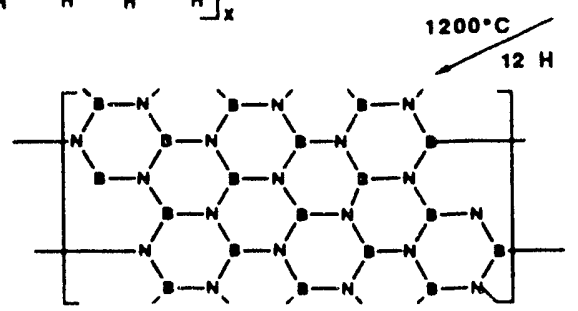

Because of its solubility, low-temperature decomposition, and high ceramic and chemical yields, polyborazylene would appear to be the ideal chemical precursor to 
boron nitride and thus enable many important applications. We have now, in fact, employed both polyborazylene and polyvinylborazine for the production of $h-B N$ coatings on on alumina, silicon carbide, silicon nitride and carbon fibers by simply dipping yarn in polymer solutions then heating the coated fibers to $>900^{\circ} \mathrm{C}$. Such coatings are of great technological interest since they can enhance the toughness of ceramic-matrix composites by increasing the potential for fiber pullout.

\section{Hybrid Polymers: Precursors to SiNCB and BNC Ceramic Composites}

Borazine-Modified Hydridopolysilazanes. Polysilazanes have been shown to be excellent polymeric precursors to silicon nitride or SiNC ceramic materials. ${ }^{4}$ Chemical modification of polysilazanes has been proposed as a means of modifying and enhancing the properties of the polymer and/or the final ceramic materials. For example, the incorporation of boron in the polysilazane has been claimed ${ }^{12}$ to decrease the crystallinity of the silicon nitride derived from these polymers and thereby extend the effective use-temperature of these ceramics. Given the potential importance of SiNCB materials, we have investigated in collaboration with Ed Remsen (Monsanto) and Gregg Zank (Dow-Corning) the generation of new classes of hybrid polymers that might serve as processable precursors to such composite ceramics.

We have now found 13 that the high yield synthesis of hybrid borazinesubstituted hydridopolysilazanes can be achieved by the reaction of the preformed silicon-based preceramic polymer, hydridopolysilazane (HPZ), ${ }^{14}$ with liquid borazine at moderate temperatures. The amounts of borazine incorporated into the hydridopolysilazane can be readily controlled. For example, polymers of compositions $\left.\left(\mathrm{B}_{3} \mathrm{~N}_{3} \mathrm{H}_{5}\right)_{0.02}(\mathrm{HSi})_{0.30}\left(\mathrm{Me}_{3} \mathrm{Si}\right)_{0.19} \mathrm{NH}\right)_{0.26} \mathrm{~N}_{0.23} 1$ and $\left(\mathrm{B}_{3} \mathrm{~N}_{3} \mathrm{H}_{5}\right)_{0.07}(\mathrm{HSi})_{0.34}\left(\mathrm{Me}_{3} \mathrm{Si}\right)_{0.18}(\mathrm{NH})_{0.13}-\mathrm{N}_{0.28}, 2$ were prepared by heating $\mathbf{H P Z}$ in excess borazine at $73^{\circ} \mathrm{C}$ for $2.2 \mathrm{~h}$ and $7.0 \mathrm{~h}$, respectively. The spectroscopic data for the new polymers indicate that they have retained their hydridopolysilazane backbones, but are substituted with pendant borazines by means of a borazine-boron to polymer-nitrogen linkage. Such linkages may have been formed by either hydrogen or trimethylsilane elimination reactions.

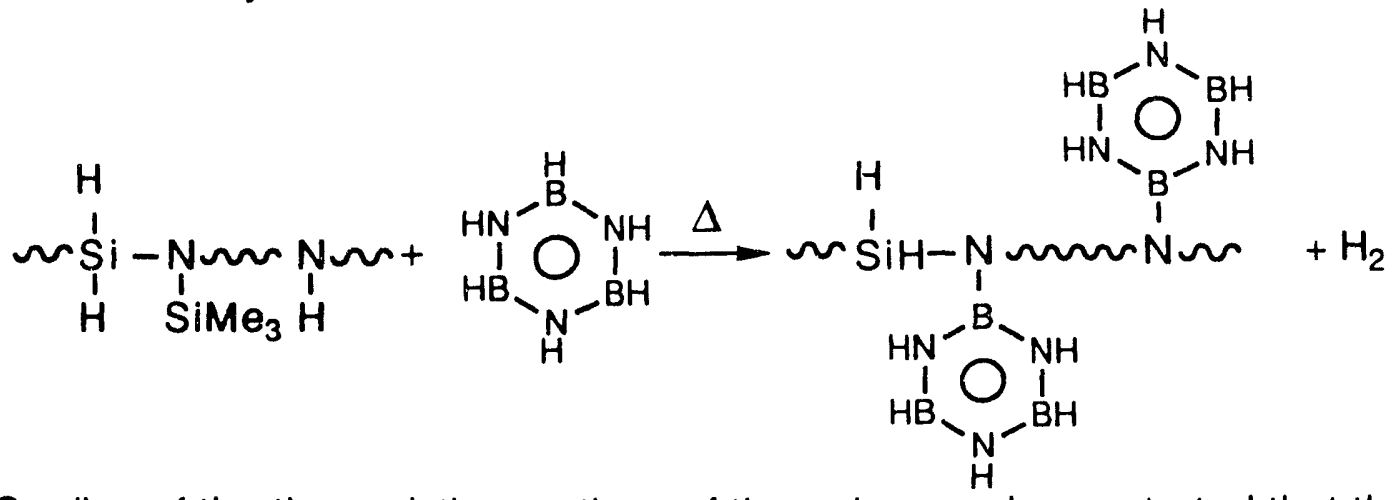

Studies of the thermolytic reactions of the polymers demonstrated that they are converted in high ceramic and chemical yields to composite SiNCB ceramic materials. The ceramic yields $(\sim 70 \%)$ to $1400^{\circ} \mathrm{C}$ are increased over that observed for the unmodified HPZ $(\sim 57 \%)$ due to both the retention of boron and nitrogen in final ceramic, and a borazine-crosslinking reaction which retards the loss of polymer backbone components. It is also very significant that, in contrast to the ceramic 
materials obtained from unmodified HPZ, the borazine-modified polymers yield ceramics that are amorphous to $1400^{\circ} \mathrm{C}$.

As shown in the Table, pyrolyses carried out to higher temperatures also demonstrated that the boron-modified ceramics are significantly more stable with respect to nitrogen loss than the ceramic derived from the unmodified HPZ.

\section{High Temperature Pyrolysis Results.}

HPZ

\begin{tabular}{|c|c|c|}
\hline Iemp. $\left({ }^{\circ} \mathrm{C}\right)$ & Char vield (\%) & Compesition \\
\hline $\begin{array}{l}1400 \\
1500 \\
1600 \\
1700 \\
1800\end{array}$ & $\begin{array}{l}62.3 \\
61.3 \\
55.5 \\
44.1 \\
42.4\end{array}$ & $\begin{array}{l}\mathrm{C}_{1.00 \mathrm{~N}_{2.35} \mathrm{Si}_{2.43}} \\
\mathrm{C}_{1.00 \mathrm{~N}_{2.42} \mathrm{Si}_{2.48}} \\
\mathrm{C}_{1.00 \mathrm{~N}_{1.66} \mathrm{Si}_{2.23}} \\
\mathrm{C}_{1.00 \mathrm{~N}_{0.13} \mathrm{Si}_{1.15}} \\
\mathrm{C}_{1.00 \mathrm{~N}_{0.03} \mathrm{Si}_{1.06}}\end{array}$ \\
\hline
\end{tabular}

Polymer :

\begin{tabular}{|c|c|c|}
\hline $\operatorname{Temn}\left({ }^{\circ} \mathrm{C}\right)$ & Charvield (\%) & Composition \\
\hline $\begin{array}{l}1400 \\
1500 \\
1600 \\
1700 \\
1800\end{array}$ & $\begin{array}{l}68.8 \\
69.9 \\
62.9 \\
59.1 \\
51.1\end{array}$ & 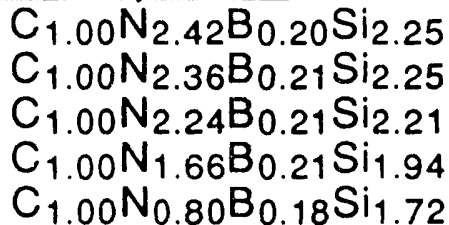 \\
\hline
\end{tabular}

Significant differences in the onset, phases and extent of crystallization in the ceramic products obtained from HPZ and the modified polymers were also observed. The ceramics resulting from the borazine-modified polymers do not show any major crystallinity until $1700^{\circ} \mathrm{C}$, at which temperature a mixture of $\alpha-\mathrm{Si}_{3} \mathrm{~N}_{4}, \beta-\mathrm{Si}_{3} \mathrm{~N}_{4}$ and $\beta-\mathrm{SiC}$ is observed. In contrast, the ceramic derived from HPZ shows substantial amounts of crystalline $\alpha-\mathrm{Si}_{3} \mathrm{~N}_{4}$ at $1500^{\circ} \mathrm{C}$, both $\alpha-\mathrm{Si}_{3} \mathrm{~N}_{4}$ and $\beta-\mathrm{SiC}$ at $1600^{\circ} \mathrm{C}$ and only $\beta-\mathrm{SiC}$ above $1700^{\circ} \mathrm{C} .15$

Because of their ease of synthesis and processability, as well as the increased thermal stabilities and reduced crystallinity of their derived ceramics, these new hybrid borazine-modified hydridopolysilazanes polymers may prove to be reasonable precursors for enhanced SiNCB fibers, matrices for ceramic-ceramic or carbon-carbon composites and/or binders for nitrogen based ceramic powders. These applications are presently under investigation.

Poly(styrene-co-B-vinylborazine) Copolymers. The discovery that soluble poly(B-vinylborazine) homopolymers could be readily formed in solution at $80^{\circ} \mathrm{C}$ with the aid of AIBN initiation has enabled the systematic production of a new soluble organic/inorganic hybrid polymers. In our initial studies ${ }^{8}$ we demonstrated the production of a new family of poly(styrene-co-B-vinylborazine) copolymers. 

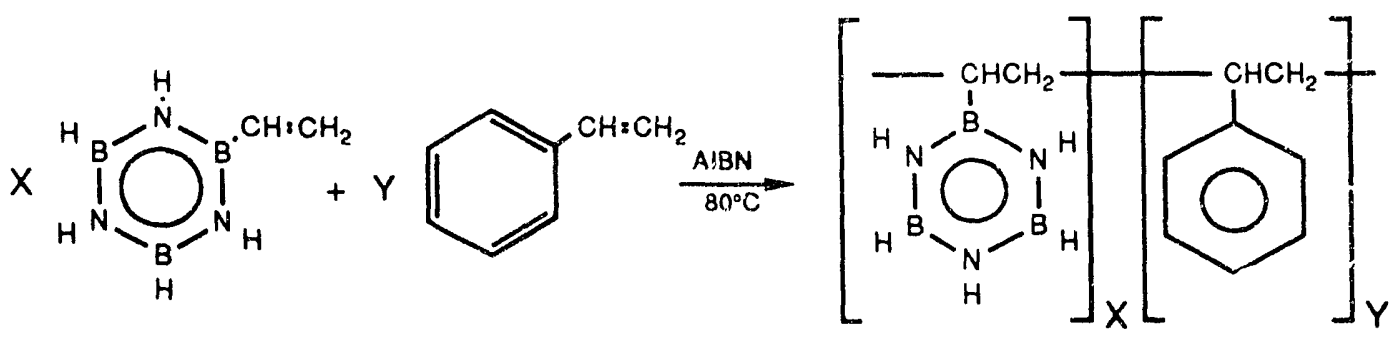

Elemental analyses and the spectroscopic data are consistent with their styrene-co-B-vinylborazine formulations. By adjusting the monomer feed ratios and the initiator concentrations, copolymers ranging in composition from 10 to $90 \%$ styrene and molecular weights from $\sim 1,000$ to $>1,000,000$ can be produced. The use of these AIBN initiated olefin copolymerization reactions are now being explored as routes to a wide variety of borazine-containing hybrid organic polymers.

\section{Precursors to Metal Borides and Metal-Boride/Nitride Composites}

Decaborane-Based Metal Boride Precursors. Metal borides ${ }^{15}$ are highmelting, extremely hard solids with high thermal stabilities and chemical inertness. Many also have metallic like conductivity and/or unusual magnetic properties. One common powder method of making bulk metal borides has been the reduction of the metal oxide with boron carbide. However, this reaction is not useful for the syntheses of coatings or shaped materials since neither the $\mathrm{MO}_{2}$ or $\mathrm{B}_{4} \mathrm{C}$ are soluble or melt at reasonable temperatures. Since soluble processable polymeric precursors to boron carbide have now been developed, we felt that a processable precursor to a metal boride could be obtained by dispersing a metal source such as $\mathrm{MO}_{2}$ or $M(O R)_{4}$ in such a precursor polymer. Heating the mixture could then result in the in situ generation of boron carbide followed by reaction to produce the boride.

Such precursor systems were obtained 17 by dispersing metal oxides, such as $\mathrm{TiO}_{2}$, in the decaborane dicyanopentane polymer, $\left(-\mathrm{B}_{10} \mathrm{H}_{12} \mathrm{NC}-\left(\mathrm{CH}_{2}\right){ }_{5}-\mathrm{CN}-\right)_{x}$.

Subsequent pyrolysis of the dispersions at temperatures above $1400^{\circ} \mathrm{C}$ afford metal borides, including $\mathrm{TiB}_{2}, \mathrm{ZrB}_{2}, \mathrm{NbB}_{2}, \mathrm{TaB}_{2}$ and $\mathrm{HfB}_{2}$ in high chemical and ceramic yields.

$$
\begin{gathered}
\mathrm{fB}_{10} \mathrm{H}_{12} \mathrm{~N}=\mathrm{C}\left(\mathrm{CH}_{2}\right)_{5} \mathrm{C}=\mathrm{N} \mathrm{f}_{\mathrm{n}}+\mathrm{MO}_{2} \longrightarrow \mathrm{MB}_{2} \\
\mathrm{M}=\mathrm{Ti}, \mathrm{Zr}, \mathrm{Hf}, \mathrm{Nb}, \mathrm{Ta}
\end{gathered}
$$

Elemental analyses of the $\mathrm{TiB}_{2}, \mathrm{ZrB}_{2}, \mathrm{NbB}_{2}, \mathrm{TaB}_{2}$ and $\mathrm{HfB}_{2}$ materials showed excellent purities. The metal borides powders were found to be highly crystalline and with grain sizes in the submicron range at $1400^{\circ}$. Based on ceramic conversion studies of both the polymer and the dispersions, the reaction is proposed to involve the in situ generation of boron carbide and carbon followed by solid state reduction of metal oxides to produce the borides.

We have also found that, depending upon the metal oxide particle size and the polymer solution viscosity, the metal oxide particles will stay suspended in the solution 
and that this precursor mixture may then be used for the generation of excellent metal boride coatings. We have, for example, achieved $\mathrm{TiB}_{2}$ coatings on graphite with this method. Such coatings are of great potential technological importance for the protection of carbon from attack by molten aluminum in Hall cells and for the protection of carbon fibers in metal matrix composite materials. We are now in the process of expanding our coating work to include a variety of substrates and metal borides.

Polyborazylene-Based Precursors to $\mathrm{TiB}_{2} / \mathrm{TiN}$ Composites. The results described in the previous section, yielding metal borides from a boron-carbon based polymer, suggested that the reactions of a metal with a boron-nitrogen polymer, such as polyborazylene, might lead to incorporation of both polymer boron and nitrogen atoms to produce new composite metal-nitride/metal-boride materials, which may have improved properties over individual metal borides or nitrides.

Such a titanium boride/titanium nitride precursor system was made ${ }^{18}$ by dispersing titanium powder into polyborazylene. Final ceramic materials were prepared by pyrolysis of either powders or shaped green bodies under inert atmosphere.

$$
\left(\mathrm{B}_{3} \mathrm{~N}_{3} \mathrm{H}_{4}\right)_{x}+\mathrm{Ti} \stackrel{\Delta}{\longrightarrow} \mathrm{TiN} / \mathrm{TiB}_{2}+\mathrm{H}_{2}
$$

Shaped green bodies were made by isostatic pressing of polymer/titanium dispersions. Ceramic bars with excellent shape retention in observed ceramic yields of $91-96 \%$, were then achieved by heating the green bodies to $1450^{\circ} \mathrm{C}$. X-ray diffraction and TEM studies ${ }^{19}$ of the ceramic conversion reaction have shown that the material goes through several changes in composition and crystallinity as the processing temperature is increased. Up to $800^{\circ} \mathrm{C}$ there is little reaction between the polymer and the titanium metal. As the temperature is increased, $25-50 \mathrm{~nm}$ size crystals of TiN nucleate. At $1200^{\circ} \mathrm{C}$ crystalline $\mathrm{TiB}_{2}$ is observed to form. The final morphology contains homogeneous distribution of $500 \mathrm{~nm}$ size grains with residual amorphous phase at triple points and along grain boundaries.

The preparations of $\mathrm{TiB}_{2} / \mathrm{TiN}$ and $\mathrm{TiB}_{2} / \mathrm{Ti}(\mathrm{CN})$ composite materials by sintering $\mathrm{TiB}_{2}$ and TiN or TiCN powders at high temperatures have previously been reported. 20 $\mathrm{TiB}_{2} / \mathrm{TiN}$ composite coatings have also been achieved by CVD methods. ${ }^{21}$ The new polymer route discussed above is, however, the only direct chemical method that can be used to produce shaped titanium boride/nitride composites, consisting of intimately mixed polycrystals with grain sizes on the order of nanometers, in high ceramic and chemical yields. The dependence of the crystal size and distribution on the reaction/ sinter temperature, the evolution of microstructure and the properties of the final composite material, such as conductivity and hardness, are currently under investigation. We are also exploring the reactions of polyborazylene with other metals and soluble metal complexes with the goal of developing a range of new metal boride/nitride precursor systems that will allow the formation of both shaped bodies and coatings. 
New Boron-Nitrogen Clusters (Jointly sponsored by DOE and DFG)

During the last year we have initiated investigations of new synthetic routes to nitrogen containing boron-clusters. Such boron-nitrogen clusters could, because of their expected thermal and hydrolytic stabilities, might prove an attractive alternative to borazine for the incorporation of boron and nitrogen into a polymer. Our initial studies focused on the reactions of polyhedral boron compounds with azides and imimes and have resulted in the synthesis and structural characterization of the first example of a new class of hybrid fused ring-cluster triazene-thiaborane compound, $22 m_{2}(4, e \times 0-9)$ (1-SiMe $\left.3-3-\mathrm{H}-\mathrm{N}_{3}\right)$-arachno-6-SB $\mathrm{H}_{10}$ and the production of a series of new imine substituted boranes, ${ }^{23}$ such as endo-9- $((t-\mathrm{Bu}) \mathrm{MeC}=\mathrm{NH})$ - arachno-6-SBgH 11 We are presently exploring new reactions of polyhedral boranes with both saturated and unsaturated nitrogen ligands as possible routes to new hybrid boron-nitrogen clusters and aza-cage/ring compounds.

\section{References}

1 For a general discussion of inorganic polymers, see Zeldin, M.; Wynne, K. J.; Allcock, H. R., Eds. Inorganic and Organometallic Polymers ACS Symposium Series 360; American Chemical Society: Washington, DC, 1988. For general references on the use of ceramic precursors see: (a) Wynne, K. J.; Rice, R. W. Ann. Rev. Mater. Sci. 1984, 14, 297-334. (b) Rice, R. W. Am. Cer. Soc. Bull. 1983, 62, 889-892. (c) Hench, L. L.; Ulirich, D. R., Eds. Ultrastructure Processing of Ceramics, Glasses, and Composites. Wiley: New York, 1984; pp. 235-312 and references therein. Yajima, S. Am. Ceram. Soc. Bull. 1983, 62, 893.

4 Baney, R.; Chandra, G. in Encyclopedia of Polymer Science and Engineering, Wiley: New York, 1988, 13, 312-344.

5 For a review of chemical precursor routes and properties of boron nitride, see: Paine, R. T.; Niarula, C. K. Chem. Rev. 1990, 90, 73-92.

6 For general references see: (a) Mirabelli, M. G. L.; Lynch, A. T.; Sneddon, L. G. Solid State lonics 1989, 32/33, 655-660. (b) Sneddon, L. G.; Mirabelli, M. G. L.; Lynch, A. T.; Fazın, P. J.; Su, K.; Beck, J. S. Pure and Applied Chemistry 1991, 63, 407-410. (c) Su, K.; Fazen, P. J.; Lynch, A. T.; Remsen, E. E.; Beck J. S. in Inorganic and Organometallic Oligomers and Polymers, R. M. Laine and J. F. Harrod eds., Kluwer: Dordrecht (Netherlands) 1991. (d) Beck, J. S.; Albani, C.

7 R.; McGhie, A. R.; Rothman, J. B.; Sneddon, L. G. Chem. Mater. 1989, 1,4 (b) Lynch, A. T.; Sneddon, L. G. J. Am. Chem. Soc. 1989, 111, 6201-6209. (a) Su, K.; Remsen, E. E.; Thompson, H.; Sneddon, L. G. Macromolecules, 1991, 24, 3760-3766. (b) Su, K.; Remsen, E. E.; Thompson, H.; Sneddon, L. G. Polymer Preprints 1991, 32, 481-482.

9 Fazen, P. J.; Beck, J. S.; Lynch, A. T;. Remsen, E. E.; Sneddon, L. G. Chemistry of Materials 1990, 2, 96-97.

10 Fazen, P. J.; Remsen, E. E.; Sneddon, L. G. Polymer Preprints, 1991, 32, 544-545.

11 Fazen, P. ¿ ; Remsen, E. E.; Sneddon, L. G., in preparation. 
(a) Yajima, S.; Iwa, T.; Yamaura, T.; Okamura, K.; Hasegawa, Y. J. Mater. Sci. 1981, 16, 1349-1355. (b) Chandra, G.; Zank, G. A. U. S. Patent \# 4,762,895, Aug., 1988. (c) Burns, G. T.; Zank, G. A. U. S. Patent \# 4,945,072, July, 1990. (d) Seyferth, D.; Bryson, N.; Workman, D. P.; Sobon, C. A. J. Am. Ceram. Soc. 1991, 74, 2687-2689. (e) Funayama, O.; Kato, T.; Tashiro, Y.; Isoda, T. International Organosilicon Conference, July, 1990. (f) Funayama, O.; Arai, M.; Tashiro, Y.; Isoda, T.; Sato, K. U. S. Patent \# 5,030,744, July, 9, 1991. (g) Seyferth, D.; Plenio, H.; Rees, W. S. Jr.; Buchner, K. In Frontiers of Organosilicon Chemistry; Bassindale, A. R.; Gaspar, P. P., Eds., Royal Society: London, 1991, pp 15-27. (h) Sukumar, V.; Schmidt, W. R.; Garcia, R.; Doremus, R. H.; Interrante, L. V. Materials Letters 1990, 9, 117-120. (i) Schmidt, W. R.; Hurley, Jr., W. J.; Sukumar, V.; Doremus, R. H.; Interrante, L. V. Mat. Res. Soc. Symp. Proc. 1990, 171, 79-85.

13 (a) Su, K.; Remsen, E. E.; Zank, G. A.; Sneddon, L. G. Chem. Mater. 1993, 5, 547-556. (b) Su, K.; Remsen, E. E.; Zank, G. A. Sneddon, L. G. Polymer Preprints 1993, 34, 334-335.

14 (a) Cannady, J. P. US Patent \# 4,535,007, August 13, 1985. (b) Cannady, J. P. US Patent \# 4,540,803, September 10, 1985. (c) Cannady, J. P. US Patent \# 4,543,344 September 24, 1985. (d) Lagrow, G. E.; Lin, T. F.; Lipowitz, J.; Reach, R. S. Ceram. Bull. 1987, 66, 363-7.

Burns, G. T.; Ewald, J. A.; Mukherjee, K. J. Mater. Sci. 1992, 27, 3599-3604.

16 For general reviews of the syntheses, structures and properties of metal borides see: (a) Greenwood, N. N.; Parish, R. V.; Thornton, P. Quart. Rev 1966, 20, 441-464. (b) Matkovich, V. I. Boron and Refractory Borides Springer-Verlag: New York, 1977. (c) Post, B. in Boron, Metallo-Boron Compounds and Boranes Adams, R. M., ed., Interscience:New York, 1964, pp 301-372 (d) Greenwood, N. N. The Chemistry of Boron, Pergamon: New York, 1975, pp 697-731. (e) Thompson, R. in Progress in Boron Chemistry 2, Pergamon: New York, 1970, pp 173-230. (f) Hoard, J. L.; Hughes, R. E. in The Chemistry of Boron and Its Compounds, Muetterties, E. L. ed., Wiley: New York, 1967, pp 25-154.

17 (a) Su, K.; Sneddon, L. G. Chem. Mat. 1991, 3, 10-12. (b) Su, K.; Sneddon, L. G., submitted.

18 Su, K.; Nowakowski, M.; Bonnell, D.; Sneddon, L. G. Chem. Mat. 1992, 4, 1139 1141.

19 (a) Nowakowski, M.; Su, K.; Sneddon, L. G.; Bonnell, D. Mat. Res. Soc. Proc. 1993, 286, 425-430. (b) Szabo, V.; Nowakowski, M.; Su, K.; Sneddon, L. G.; Ruhle, M.; Bonnell, D. Mat. Res. Soc. Proc. 1993, 286, 431-440.

(c) Nowakowski, M.; Su, K.; Szabo, V.; Sneddon, L. G.; Ruhle, M.; Bonnell, D. J. Mat. Res. submitted.

20 (a) Shobu, K.; Watanabe, T.; Enomoto, Y.; Umeda, K.; Tsuya, Y. J. Am. Ceram. Soc. 1987, 70, C103-C104. (b) Watanabe, T.; Yamamoto, H.; Shobu, K.; Sakamoto, T. J. Am. Ceram. Soc. 1988, 71, C202-C204.

21 Becht, J. G.; Van der Put, P. J.; Schoonman, J. Solid State Ionics 1989, 32, 789-794.

22 Kupper, S.; Carroll, P. J.; Sneddon, L. G. J. Am. Chem. Soc. 1992, 114, 4914.

23 Kupper, S.; Carroll, P. J.; Sneddon, L. G. Inorg. Chem. 1992, 31, 4921-4925. 


\section{Publications Acknowledging DOE Support (1990-present)}

1. P. J. Fazen, J. S. Beck, A. T. Lynch, E. E. Remsen and L. G. Sneddon "Thermally Induced Borazine Dehydropolymerization Reactions. Synthesis and Ceramic Conversion Reactios of a New High Yield Polymeric Precursor to Boron Nitride" Chemistry of Materials 1990, 2, 96-97.

2. L. G. Sneddon, K. Su, P. J. Fazen, A. T. Lynch, E. E. Remsen and J. S. Beck "Polymeric Precursors to Boron Nitride Ceramics" in Inorganic and Organometallic Oligomers and Polymers R. M. Laine and J. F. Harrod eds., Kluwer: Dordrecht (Netherlands) 1991.

3. L. G. Sneddon, M. G. L. Mirabelli, A. T. Lynch, P. J. Fazen, K. Su and J. S. Beck "Polymeric Precursors to Boron Based Ceramics" Pure and Applied Chemistry 1991, 63, 407-410.

4. K. Su, E. E. Remsen, H. Thompson and L. G. Sneddon " Syntheses and Properities of Poly(vinylborazine) and Poly(vinylborazine/styrene) Copolymers" Macromolecules 1991, 24, 3760-3766.

5. K. Su and L. G. Sneddon "Polymer Precursor Routes to Metal Borides: Syntheses of $\mathrm{TiB}_{2}$ and $\mathrm{ZrB}_{2}$ " Chem. Mater. 1991, 3, 10-12.

6. K. Su, E. E. Remsen, H. M. Thompson and L. G. Sneddon "Synthesis of Poly(B-Vinylborazine) and Poly(Styrene-co-B-Vinylborazine) Copolymers" Polymer Preprints, 1991, 32, 481-482.

7. P. J. Fazen, E. E. Remsen and L. G. Sneddon "Synthesis and Ceramic Conversion Reactions of Polyborazylene" Polymer Preprints, 1991, 32, 544-545.

8. S. Kupper, P. J. Carroll, L. G. Sneddon "Synthesis and Structural Characterization of a Hybrid Triazene-Thiaborane Cluster: $\mu$ - $(e \times 0-9,4)-(1-$ $\mathrm{SiMe}_{3}-3-\mathrm{H}-\mathrm{N}_{3}$ )-arachno-6-SBgH ${ }_{10}$ " J. Am. Chem. Soc. 1992, 114, 4914-5.

9. S. Kupper, P. J. Carroll, L. G. Sneddon "Synthesis of nido-SBgH $\mathrm{H}_{11}$ with Imines. Structural Characterization of endo-9-((t-Bu)MeC=NH)-arachno-6$\mathrm{SBgH}_{11} "$ Inorg. Chem, 1992, 31, 4921-4925.

10. K. Su, M. Nowakowski, D. Bonnell and L. G. Sneddon "A Polymer Precursor Route to $\mathrm{TiB}_{2} / \mathrm{TiN}$ Nanocomposites" Chemi. of Mater. 1992, 31, 1139-1141.

11. K. Su, E. E. Remsen, G. Zank and L. G. Sneddon "Synthesis, Characterization and Ceramic Conversion Reactions of Borazine-Modified Hydridopolysilazanes" Polymer Preprints 1993, 34, 334-335. 
12. M. Nowakowski, K. Su, L. G. Sneddon and D. Bonnell "Synthesis, Processing and Phase Evolution of $\mathrm{TiN} / \mathrm{TiB}_{2}$ Composites from a Polymeric Precursor" Materials Res. Soc. Proc. 1993, 286, 425-430..

13. V. Szabo, M. Nowakowski, K. Su, L. G. Sneddon, M. Ruhle and D. Bonnell "Microstructure Evolution in $\mathrm{TiB}_{2} / \mathrm{TiN}$ Composites"Materials Res. Soc. Proc. 1993, 286, 430-440.

14. K. Mazighi, P. J. Carroll and L. G. Sneddon "Transition Metal Promoted Reactions of boron Hydrides 13. Platinum Catalyzed Decaborane/OlefinAddition Reactions" Inorg. Chem. 1993, 32, 1963-1969.

15. K. Su, E. E. Remsen, G. Zani and L. G. Sneddon "Synthesis, characterization and Coramic Conversion Reactions of Eorazine-Modified Hydridopolysilazanes: New Polymeric Precursors SiNCBComposites." Chemistry of Materials 1993, 5, 547-556.

16. M. Nowakowski, K. Su, V. Szabo, L. G. Sneddon, M. Ruhle and D. Bonnell "Synthesis, Piocessing and Microstruc: ural Evolution of $\mathrm{TiB}_{2} / \mathrm{TiN}$ Composites from a Polymeric Precursor"J. of Materials Res, submitted.

17. K. Su and L. G. Sneddon "Polymer Precursor Routes to Metal Borides" in preparation.

18. P. J. Fazen, :-. E. Remsen and L. G. Sneddon "Synthesis and Cerarnic Conversion Reactions of Polyborazylene" in preparation.

\section{Statement of Unexpended Funds}

It is estimated that no funds will remain unexpended or uncommitted at the end of the final budget period. 


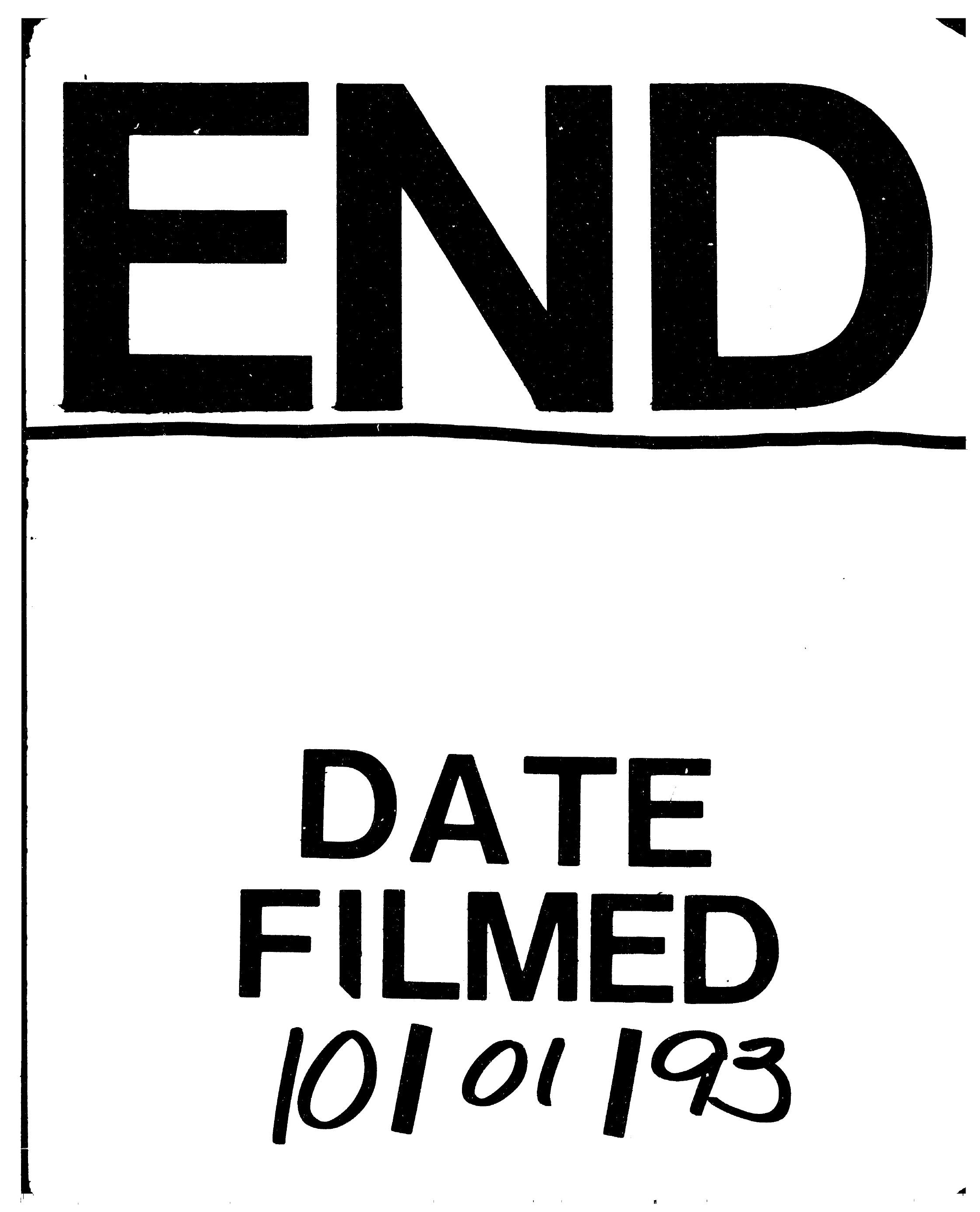


